\title{
GPS Error in Studies Addressing Animal Movements and Activities
}

\author{
David C. Ganskopp ${ }^{1}$ and Dustin D. Johnson ${ }^{2}$ \\ Authors are ${ }^{1}$ Rangeland Scientist, United States Department of Agriculture-Agricultural Research Service, Eastern Oregon Agricultural Research Center, \\ 67826-A Hwy 205, Burns, OR 97720; and ${ }^{2}$ Rangeland Management Specialist, United States Department of Interior-Bureau of Land Management,
} 2891 Hwy 20 W, Hines, OR 97738.

\begin{abstract}
Global Positioning System (GPS) error, associated with free-ranging animal studies, remains a concern in range/animal research. For distance measures, errors may be additive over time and increase as sampling frequency intensifies. The first study assayed effects of coordinate integration time (10 hourly intervals), 10 GPS collars, and range of unit movement (0 to $90 \mathrm{~m}$ in $10-\mathrm{m}$ intervals as treatments) on bias of GPS measures of distance. "Bias" was the difference between measured distances and distances derived from GPS coordinates of units moved over a surveyed grid. A second study evaluated four methods (regression modeling, minimum distance threshold, motion sensor threshold, and a combined minimum distance/motion sensor technique) for extracting perceived movements from GPS data acquired from cattle. A classification assessment compared observation data of cattle with their corresponding GPS records after filtering by the four techniques. Except for immobile GPS collars in study 1, bias of distance measures was inconsequential for movements ranging from 10 to $90 \mathrm{~m}$ (differentially corrected mean bias $=0.18 \mathrm{~m} \pm 0.12 \mathrm{~m} \mathrm{SE}$ ). When collars were immobile, GPS error generated about $1.7 \mathrm{~m} \pm 0.7 \mathrm{~m} \mathrm{SE}$ of perceived travel per record with postdifferentially corrected coordinates $(P<0.05)$, and $3.9 \mathrm{~m} \pm 0.8 \mathrm{~m}$ SE with uncorrected data. At specific times, post-differential correction failures can affect $(P \leq 0.05)$ GPS measures of distance. Using any of four proposed techniques, one may effectively filter data sets to remove perceived travel accrued when cattle were resting with $81 \%$ to $92 \%$ of resting intervals correctly classified. The most effective regression technique suggested cattle travels were overestimated by about $15.2 \%$ or $1.15 \mathrm{~km}$ daily without filtering.
\end{abstract}

\section{Resumen}

El error de los Sistemas de Posicionamiento Global (GPS), asociado al libre movimiento en los estudios con animales, sigue siendo una preocupación en la investigación animal en pastizales. Para mediciones de distancia, los errores pueden ser aditivos a través del tiempo, e incrementarse conforme la frecuencia de muestreo se intensifica. El primer estudio evaluó los efectos de la integración coordinada del tiempo (observaciones cada hora durante 10 horas, en 10 collares de GPS) y el rango de la unidad de movimiento ( 0 a 90 m, en intervalos de $10 \mathrm{~m}$ como tratamientos) en el sesgo de las mediciones de distancia del GPS. El "sesgo" fue la diferencia entre las distancias medidas y las derivadas de las coordenadas del GPS de unidades movidas a través de una cuadrícula muestreada. En un segundo estudio se evaluaron cuatro métodos (modelado con regresión, umbral de mínima distancia, umbral de sensor de movimiento, y la combinación de distancia mínima/técnica de sensor de movimiento) para extraer los movimiento percibidos a partir de datos de GPS adquiridos con ganado. Una evaluación de la clasificación comparó los datos de observación del ganado con sus registros correspondientes de GPS, después de filtrarlos con las cuatro técnicas. Excepto por los collares inmóviles de GPS del estudio uno, el sesgo de las medidas de distancia no fue de consecuencias para los movimientos en el rango de 10 a $90 \mathrm{~m}$ (media del sesgo corregida diferencialmente $=0.18 \mathrm{~m} \pm 0.12 \mathrm{~m} \mathrm{EE}$ ). Cuando los collares estuvieron inmóviles, el error generado del GPS fue aproximadamente $1.7 \mathrm{~m} \pm 0.7 \mathrm{~m}$ EE del viaje percibido por registro, después de corregir diferencialmente las coordenadas $(P<0.05)$, y $3.9 \mathrm{~m} \pm 0.8 \mathrm{~m} \mathrm{EE}$ con los datos sin corregir. En tiempos específicos, los fracasos de la corrección diferencial posterior puede afectar $(P \leq 0.05)$ las medidas de distancia del GPS. Usando cualquiera de las cuatro técnicas propuestas se pueden filtrar efectivamente las bases de datos para remover el viaje percibido acumulado cuando el ganado esta descansando, con $81 \%$ a $92 \%$ de los intervalos de descanso correctamente clasificados. La técnica de regresión más efectiva sugirió, que sin filtrar los datos, los viajes del ganado fueron sobreestimados en aproximadamente $15.2 \%$ o $1.15 \mathrm{~km}$ diarios.

Key Words: global positioning system collars, grazing behavior, cattle, activity, data filtering, technique, method, differential correction

The Eastern Oregon Agricultural Research Center is jointly funded by the Agricultural Research Service and Oregon State University.

Proprietary or trade names are for information only and do not convey endorsement of one product over another

Correspondence: David Ganskopp, United States Department of Agriculture, Eastern Oregon Agricultural Research Center, 67826-A Hwy 205, Burns, OR 97720. Email: david. ganskopp@oregonstate.edu

Manuscript received 6 March 2006; manuscript accepted 1 April 2007.

\section{INTRODUCTION}

Global Positioning System (GPS) units derive positions from internal receivers monitoring signals from an array of 24 earthorbiting satellites. Operating principles, degree of inherent error, and procedures used to minimize error associated with the Global Positioning System may be found in Hurn (1989) and Hurn (1993). Because GPS collars worn by medium- to large-sized animals appear to have little effect on behavior 
(Rutter et al. 1997), the technology offers great potential for documenting free-ranging animal movements (Rodgers and Anson 1994; Rodgers et al. 1996; Agouridis et al. 2004), resource use (Mourão and Medri 2002), and their activities (Ungar et al. 2005).

One concern in studies of animal behavior with GPS collars is the potential inflationary effect of system error on measures of animal movement (Pépin et al. 2004). GPS accuracy for a given record may be affected by atmospheric conditions, satellite geometry, satellite or receiver clock error, satellite orbit error, multipath effects (bounced signals) (Hurn 1993), as well as topography, overhead canopies, or adjacent structures (Moen et al. 1996; Di Orio et al. 2003). To date, assessments of GPS error have focused on the accuracy of individual coordinates relative to their true position and not measures of distance.

The reality of GPS error can potentially bias measures of distance and velocity and cause misclassifications of an animal's activities or misrepresentations of distances traveled (Ungar et al. 2005). For distance measures, error may be additive over time and its contributions inflated if sampling intervals are short or animal movements minimal (Heezen and Tester 1967).

This study addressed two objectives. The first was to assess contributing effects of individual GPS units, time of day, and extent of unit movement on accuracy of distance measures derived from GPS collar data. The second was an evaluation of four proposed techniques for filtering perceived distance measures accrued when animals were indeed inactive and stationary.

Moen et al. (1996), while evaluating canopy effects on GPS collar performance, proposed that spurious records linked to inactive animals be withdrawn from datasets. Proposed techniques included removing coordinates if accompanying motion sensor data indicated animals were inactive or extracting records when perceived movements were within the realm of typical GPS error (Moen et al. 1996).

With either method, accurate thresholds for discerning active and stationary periods are likely best obtained by recording the precise times collared subjects transition between activities (Ganskopp 2001). Those data are subsequently paired with time-stamped collar records and assumptions (Ganskopp and Bohnert 2006) or statistical techniques (Ganskopp 2001; Ungar et al. 2005) used to assign an activity to each record or estimate duration of an activity within a given time period. A study using these methods in Oregon suggested cattle rested (standing or bedded) for $10.1 \mathrm{~h}$ and foraged for $11.0 \mathrm{~h}$ each day (Ganskopp 2001). The remaining $2.9 \mathrm{~h}$ were divided among walking $(1.8 \mathrm{~h})$, drinking $(0.3 \mathrm{~h})$, and mineral consumption (0.3 h) (Ganskopp 2001).

When animals cannot be observed, other methods for identifying activities and discerning real or perceived travels are needed. These might include time- or frequency-scaled graphic renderings of distances traveled between records and analyses for thresholds (Ungar et al. 2005). Other ideas include assessments of turning angles or sorting of data for spatially clustered coordinates.

In practice, however, we have noted cattle often exhibit finescale movements in favored feeding locales. Thus, a series of small distance accruals may or may not accurately discriminate

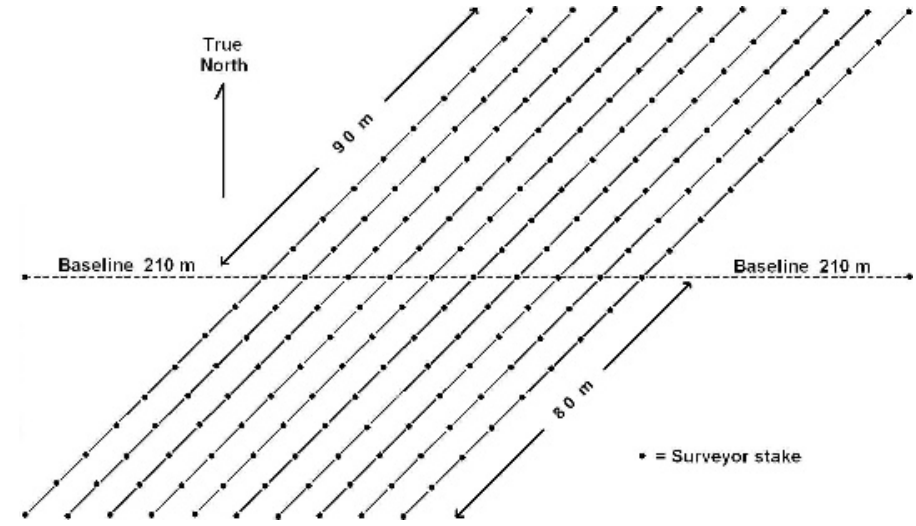

Figure 1. Field design used to assess discrepancies between surveyed distance measures and measures of movement derived from Lotek 2200 GPS collar coordinates acquired as units were moved at hourly intervals at the Eastern Oregon Agricultural Research Center near Burns, Oregon, in December 2005.

between an animal's stationary and foraging endeavors. To account for bouts of "near static" foraging ( $\leq 10 \mathrm{~m}$ diameter), we suggest that a blending of minimum distance and motion sensor thresholds might refine identification and potential removal of erroneous distance accruals.

\section{MATERIALS AND METHODS}

\section{Study 1. Sources and Effects of GPS Error on Distance Measures}

Study Site and Plot Layout. The study plot was established in a 25-ha meadow on the Eastern Oregon Agricultural Research Center (lat $43^{\circ} 30.9^{\prime} \mathrm{N}$, long $119^{\circ} 01.4^{\prime} \mathrm{W}$; elevation $1242 \mathrm{~m}$; WGS-1984) approximately $8 \mathrm{~km}$ south-southeast of Burns, Oregon. Initially a $210-\mathrm{m}$ baseline on a $90^{\circ}$ azimuth was surveyed and staked in a treeless meadow (Fig. 1). The nearest potentially interfering buildings were $200 \mathrm{~m}$ distant. Subsequently 10 surveyor stakes were placed at $10-\mathrm{m}$ intervals on the initial line with their combined length $(100 \mathrm{~m})$ centered on the baseline. Thereafter, 10 parallel branches, on $10-\mathrm{m}$ centers and oriented on a $45^{\circ}$ azimuth, were staked across the baseline. The $45^{\circ}$ azimuth was selected for branches because GPS error for a given coordinate is almost two times greater for north-south approximations than for east-west determinations (Fig. 2). Unit movements restricted to either axis could potentially inflate ( $\mathrm{Y}$ axis) or underestimate (X axis) overall error. Ninety meters of each branch extended northeast of the baseline, and $80 \mathrm{~m}$ extended southwest for a total length of $170 \mathrm{~m}$. Last, each branch was also staked at 10-m intervals.

GPS Collar Data. Fourteen Lotek ${ }^{\circledR}$ GPS2200 collars (Lotek Engineering Inc., Newmarket, Ontario, Canada) were used in this study. Collars have eight-channel GPS receivers allowing simultaneous use of signals from up to eight satellites. Data acquired at hourly intervals were stored in nonvolatile random access memory capable of retaining 5028 differentially correctable coordinates. With the default configuration, each stored record included collar number, date, time, latitude and longitude, elevation, dilution of precision (DOP), fix status 


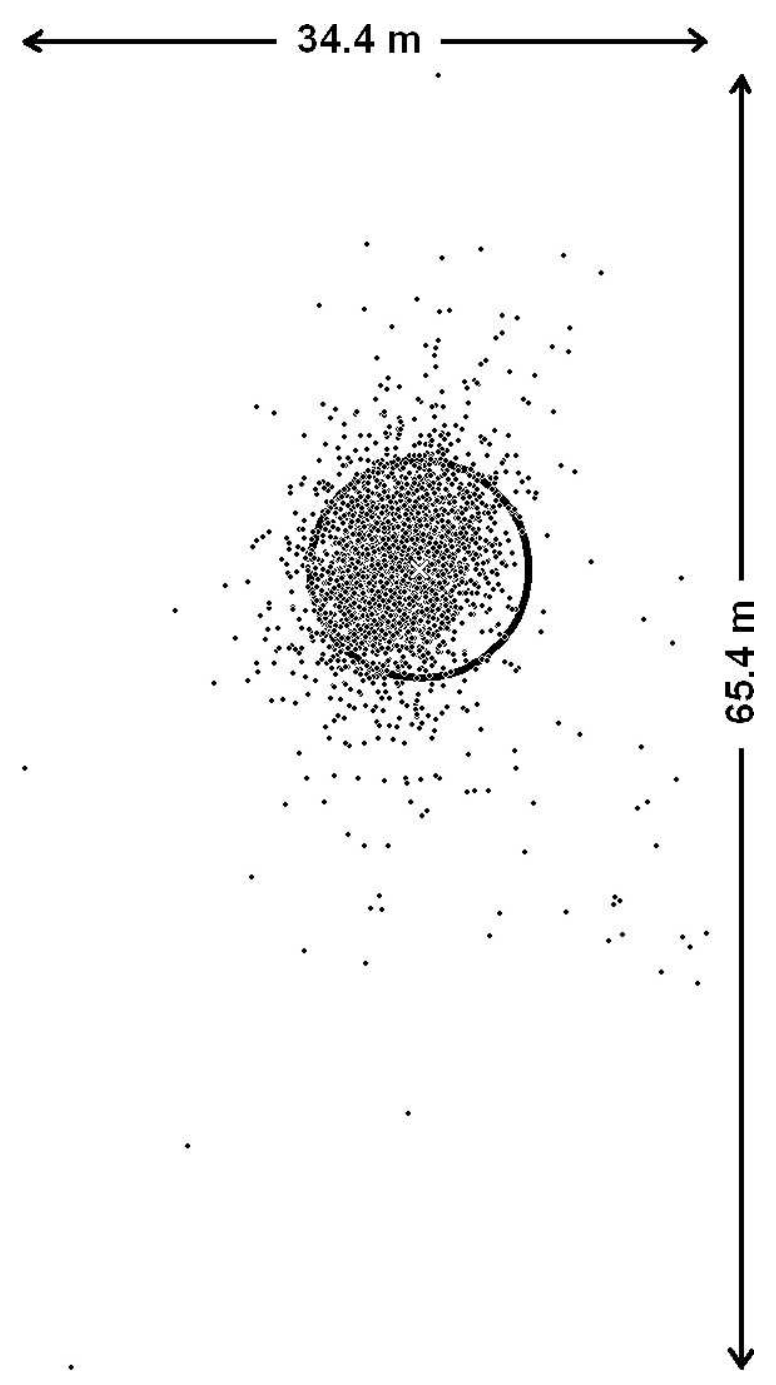

Figure 2. A rendering of 4320 differentially corrected GPS coordinates from a static Lotek 2200 GPS collar recording positions at 5-min intervals coincident with collars worn by cattle on the Northern Great Basin Experimental Range from 00:00 h 15 June through $2400 \mathrm{~h} 29$ June 2004. The circle, depicting a radius of $5.5 \mathrm{~m}$ from the mean locale $(X)$, encompasses $90 \%$ of the coordinates. An anomaly of the Geographic Positioning System is that more error occurs for northsouth or Y-axis values than among east-west or X-axis determinations.

(either two- or three-dimension), captive ball forward-backward and left-right motion sensor counts, ambient temperature, and satellite-specific data used by differential correction algorithms. Low DOP values imply a widely dispersed satellite array yielding high accuracy, while values exceeding 6 suggest a record's integrity be studied (Hurn 1993). A three-dimensional record includes a measure of elevation and requires data from a minimum of four satellites. A two-dimensional record is compiled with data from three satellites, and an elevation measure is not attempted.

Ten GPS collars were randomly allotted among the 10 branches and each initially placed on a surveyor stake at a baseline/branch junction. Antennae were centered atop stakes about $0.5 \mathrm{~m}$ above the ground. Collars were programmed to integrate a single position at hourly intervals. An onboard computer turns on the GPS at the designated time, and 40-45 s are needed to acquire data, integrate a position, and store the record. The computer then switches off the GPS unit to conserve power. Beginning and ending times were 0700 and 1700 , respectively, for a total of 11 records per collar. The initial 0700 baseline coordinate served as a beginning reference point for the initial distance measure.

Approximately 5 min after each hour, each collar was moved a designated distance along its respective branch. The 10 subsequent coordinates were used to derive GPS-based estimates of those same 10 distances. Randomized move distances were viewed as treatments $(n=10)$ and spanned 0 to $90 \mathrm{~m}$ in 10-m increments. Each collar was alternately moved in either a northerly or southerly direction unless a move extended beyond the endpoint of a branch. In those instances direction was reversed to keep collars within the confines of the study area. Last, four similarly configured collars were deployed to four randomly selected branches as controls. Control units remained stationary throughout the trial. Because of weak evidence of electronic interference between simultaneously operating GPS units in $(<1.0 \mathrm{~m})$ proximity (Di Orio et al. 2003), each control was placed at a staked position that was not used by another unit over the 10-h trial.

After final records were obtained, data were downloaded, and coordinates postdifferentially corrected using N4 v.1.1895 software (Lotek Engineering Inc.). Base station files were from a United States Forest Service/Bureau of Land Management unit near Hines, Oregon (http://www.fs.fed.us/database/gps/ burns.htm), about $6 \mathrm{~km}$ west of the study site. Corrected and uncorrected latitude/longitude coordinates were converted from decimal degrees to Universal Transverse Mercator (UTM 11N WGS 1984) form with Idrisi32 v. 32.22 software (Clark Labs, Idrisi Project, Worcester, MA) to allow algebraic determinations of distances GPS units moved between successive records.

Analyses. The dependent response variable, called "bias" in this study, was based on the distance between successive GPS records of collars and the actual distances units were moved across the surveyed plot:

$$
\text { bias }=\text { GPS derived distance }- \text { surveyed distance. }
$$

A positive sign implied GPS measures exaggerated distance, whereas negative values inferred GPS data underestimated distance.

Field layout and statistical analyses employed a $10 \times 10$ Latin Square. The 10 GPS collars were columns, hourly integration periods were rows, and the 10 move distances were randomized treatments. If a statistically significant effect (collar, integration time, or treatment) was detected in analyses of variance, a $95 \%$ confidence interval encompassing an expected bias of zero was derived. Means outside of the confidence interval were deemed statistically significant departures from zero. Independent analyses were conducted for uncorrected and post-differentially corrected data. We hypothesized there would be no GPS collar or time effects and that treatment effects would be significant only when collars remained stationary for two successive records. 
Study 2. Filtering Fine-Scale Movements Among Spatial Data

Study Site. Research was conducted using cattle in three large pastures ( $>800$ ha each) on the Northern Great Basin Experimental Range (headquartered at lat $43^{\circ} 29.4^{\prime} \mathrm{N}$, long $119^{\circ} 42.7^{\prime} \mathrm{W}$ WGS-1984; elevation $1420 \mathrm{~m}$ ), $52 \mathrm{~km}$ west of Burns, Oregon. Mean annual temperature is $7.6^{\circ} \mathrm{C}$ with recorded extremes of $-29^{\circ} \mathrm{C}$ and $42^{\circ} \mathrm{C}$. Mean annual precipitation is $289 \mathrm{~mm}$ with $60 \%$ occurring as snowfall. Vegetation is characterized by a dispersed overstory of western juniper (Juniperus occidentalis ssp. occidentalis Hook). The shrub layer may be dominated by either mountain big sagebrush (Artemisia tridentata ssp. vaseyana [Rydb.] Beetle), Wyoming big sagebrush (Artemisia tridentata ssp. wyomingensis Beetle and Young), or low sagebrush (Artemisia arbuscula Nutt.) Most prominent grasses include bluebunch wheatgrass (Pseudoroegneria spicata [Pursh] A. Löve), Idaho fescue (Festuca idahoensis Elmer), and Sandberg's bluegrass (Poa secunda J. Presl) with site-specific dominance related to soils and aspect.

GPS Collar Data. Thirteen of the previously described GPS collars were used in this study. On 12 June 2004, 60 cow-calf pairs, of Angus $\times$ Herford breeding, were transported to the Northern Great Basin Experimental Range. Twenty pairs were randomly selected for turnout in each of three pastures. Four animals from each group of 20 were randomly chosen and each fitted with a GPS collar programmed for a 5-min sampling interval beginning at $0000 \mathrm{~h}$ on 15 June 2004. None of the cattle had previous collar experience. Collars were programmed to stop 15 days later at $2400 \mathrm{~h} 29$ June. With this schedule, 288 coordinates were anticipated each day for a total of 4320 records per collar. This regimen consumed $86 \%$ of a collar's memory capacity.

Because of software limitations, collar motion sensors can accrue only maximum counts of 255 whereupon they cease incrementing. Collars can be programmed, however, to commit counts to temporary memory at specified intervals and then derive a mean for each sensor when the GPS engine switches on to obtain a position. Previous research with cattle found sensors frequently reached maximum counts with a sampling interval of 4 min when animals were grazing (Ganskopp 2001). For this trial, collars were programmed to commit counts to temporary memory at 2-min intervals. With each position integration, units wrote mean motion sensor counts for the previous two 2min periods to memory, and data acquired in the last $1 \mathrm{~min}$ of each 5-min interval were erased.

Collars were retrieved 30 June 2004, data downloaded, and coordinates differentially corrected. Coordinates were imported into Idrisi32 v. 32.22 software and converted to UTM form to facilitate algebraic derivation of distance between successive records. When differential correction of a position was not accomplished, an uncorrected position was substituted if available. Failure during the differential correction process typically involves a disparity in satellites tracked by the stationary base station and roving GPS units. When collar integrations failed completely, series of up to three consecutive records were interpolated to complete the dataset. If GPS receivers failed to obtain more than three successive fixes, that portion of the dataset was omitted from analyses. Because interpolated points are simply averages of adjacent GPS coordinates, they do not accrue additional measures of distance because they fall at the midpoint of a straight line connecting their bounding coordinates. Interpolated coordinates, however, can erroneously infer that some portion of a pasture was occupied by cattle.

Modeling Procedure. To verify time cattle devoted to specific activities, each collared animal was observed for a minimum of eight daylight hours requiring one to two observation sessions. Specific start and stop times varied because cattle were occasionally difficult to find in rugged terrain. Activities documented included foraging, walking, lying, standing, drinking, and grooming. Subsequently standing and lying times were summed within each 5 -min interval to create a seventh "resting" category. Each recorded activity was assumed to be mutually exclusive, and although cattle walk while foraging, such events were classified as foraging as long as the animal's head remained down as it moved or it was harvesting herbage from taller vegetation. Activity durations were tallied on paper at a 1-min resolution. When a cow transitioned from one activity to another, the observer would note the precise start time. If the new activity persisted for $\geq 30 \mathrm{~s}$ the start time was recorded. If an animal resumed its prior activity in $<30 \mathrm{~s}$, the interlude was ignored. With an assumption that subtle movements would fall within the realm of typical GPS error, observers did not record left-right head movements or instances where cattle simply altered orientation or reversed direction and resumed lying or standing.

Data were compiled as the total number of minutes a cow was involved in each activity within each 5-min interval. Observers carried handheld GPS units or watches set within $1 \mathrm{~s}$ of GPS time, so recorded data were well synchronized with the 5-min GPS collar sampling intervals.

Forward, stepwise regression analyses were used to select models best quantifying the duration ( $\mathrm{min}$ ) of each cow's resting activity. Independent variables acquired or derived from GPS collar data included forward-backward motion counts (sensor 1), left-right motion counts (sensor 2), distance traversed by cattle within each 5 -min interval, and ambient temperature. The resulting regression models were applied to the full collar datasets to predict the number of minutes cattle were resting during each 5-min interval. Since direct observation data were collected at a 1-min resolution, all intervals where a regression model predicted $\geq 4$ stationary min were coded as resting. Conversely all intervals where models predicted $<4$ min of resting were coded as active.

Minimum Distance Threshold Method. A single identically configured stationary GPS collar was deployed in an open meadow at the Eastern Oregon Agricultural Research Center during the 15-day trial to help detect or quantify potential GPS anomalies that may not be obvious with roving units. After differential correction of the static collar data, horizontal distances of the 4320 records from their mean location were derived. A minimum distance threshold (radius $=5.5 \mathrm{~m}$ ) was selected that encompassed $90 \%$ (Fig. 2) of the control coordinates. In highly technical evaluations of GPS error, the elliptical nature of data and associated error may be partitioned between the $\mathrm{X}$ and $\mathrm{Y}$ axes or coordinates (Sharif et al. 2004). In most applied studies where single or limited numbers of records are available for a given point, error is typically expressed as 


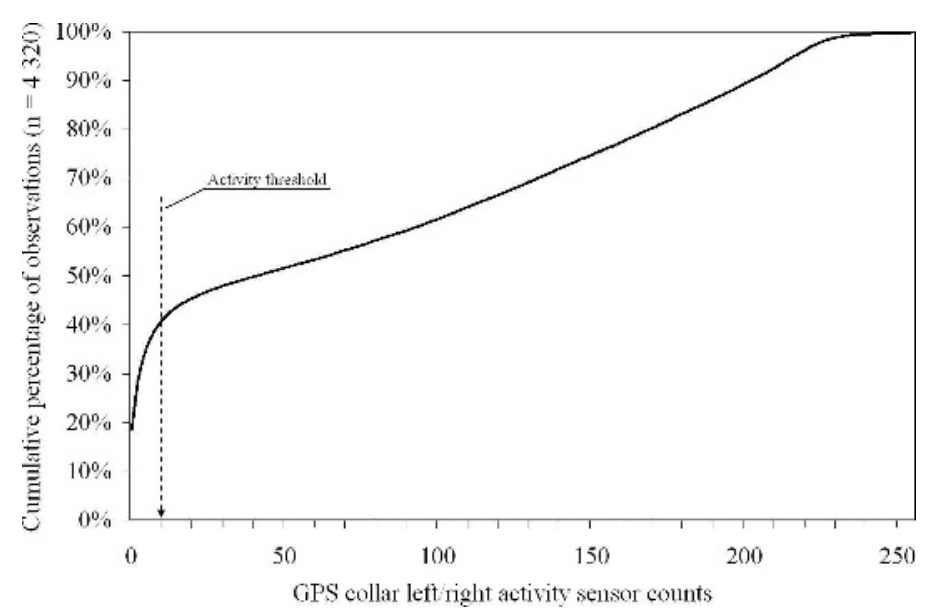

Figure 3. Cumulative percentage of increasing values from a left-right motion sensor of a GPS collar worn by a cow for 15 days on the Northern Great Basin Experimental Range near Burns, Oregon, in June 2004. Motion sensor values range from 0 to a maximum of 255 and were acquired at 5-min intervals during deployment. The selected threshold value of 10 for the left-right activity sensor, illustrated by the dashed vertical line, was the break point used to classify resting or active records of the cow.

the horizontal distance between a true and perceived position. In the latter instances, circular models with varying degrees of confidence are most often used (Rodgers et al. 1996; Di Oria et al. 2003; Sharif et al. 2004). When distance traveled by cattle between successive GPS coordinates was $\leq 5.5 \mathrm{~m}$, the activity for the destination locale was labeled resting. Conversely, if the distance between successive GPS locations exceeded $5.5 \mathrm{~m}$, the destination record was coded active.

Activity Sensor Threshold Method. Previous research with GPS collars and cattle found left-right motion sensor counts best correlated with foraging and walking activities of cattle (Ungar et al. 2005; Ganskopp and Bohnert 2006). Cumulative frequency (subsequently expressed as a percentage for presentation) of increasing activity values from the left-right activity sensor was plotted (Fig. 3) for each of the cattle-borne GPS collars (Pépin et al. 2004). We visually identified the first point of inflection of the curve as the threshold for separating resting and active periods (Fig. 3). We assumed that activity counts $\leq$ the threshold depicted a resting animal, and its associated distance measure was discounted from accumulated travels.

Combined Minimum Distance and Activity Threshold Procedure. The same procedures used to identify minimum distance and activity sensor thresholds were applied simultaneously. Only distance measures simultaneously identified as resting by both indices were excluded from totals.

Analyses. A correct-incorrect classification assessment was performed by comparing direct observation data of cattle with their corresponding 8-h period of GPS collar data filtered with each of the four procedures. Each 5-min interval of the 8-h observation period was coded resting if the sum of lying and standing activities equaled $5 \mathrm{~min}$ with the assumption that cattle were stationary for the duration. Intervals were coded active if the sum of lying and standing was less than $5 \mathrm{~min}$. The latter assumed cattle had been grazing or walking in the interim. Coded observation data were paired with the filtered GPS collar data sets to ascertain frequencies of correctly and incorrectly classified 5-min intervals with the filtering techniques.

The signed rank test (Wilcoxon 1945) was used to test two hypotheses. The first null hypothesis assumed the four filtering methods correctly identified resting intervals with equal proficiency. The second null hypothesis assumed that within a filtering method incorrectly flagged active and incorrectly flagged resting designations occurred with equal frequency. $P$ values $\leq 0.05$ were deemed significant.

\section{RESULTS AND DISCUSSION}

\section{Study 1. Sources and Effects of GPS Error on Distance Measures}

GPS Collar Performance and Differential Correction. All collars successfully acquired their 11 scheduled records. Among manipulated collars, five units contained a full complement of three-dimensional (3-D) coordinates. The remaining five units each integrated a single two-dimensional (2-D) record. Three of the $2-\mathrm{D}$ records occurred at $1400 \mathrm{~h}$ and 2 at $1600 \mathrm{~h}$. Dilution of precision (DOP) values averaged 2.2 $\pm 0.05 \mathrm{SE}$ and ranged between 1.4 and 3.5 for raw data.

After differential correction, 2 of 110 coordinates from the manipulated collars were labeled as 2-D. With differential correction, DOP values degraded slightly with values ranging from 1.7 to $5.3(\overline{\mathrm{X}}=2.7 \pm 0.06 \mathrm{SE})$.

Post-differential correction software could not correct any of the $1600 \mathrm{~h}$ records, most likely because of limited satellite availability. During earlier and later portions of the day, all GPS collars accessed seven to eight satellites. At $1600 \mathrm{~h}$, however, visible satellite count declined to six with one satellite near the horizon ( $17^{\circ}$ elevation). The GPS unit software and differential correction algorithms specified signals originating from satellites $<10^{\circ}$ above the horizon be excluded from consideration, a practice improving accuracy by ignoring lowangle signals possibly distorted by the ionosphere. We cannot, however, fully explain the $1600 \mathrm{~h}$ differential correction anomaly.

Statistical Analyses of Bias. With uncorrected data, mean bias of distance measures across collars, times, and treatments was $0.32 \mathrm{~m} \pm 0.24 \mathrm{~m} \mathrm{SE}$. Analysis of variance of raw data revealed treatment was the only significant effect $(P<0.01)$. $P$ values for time and collar effects were 0.14 and 0.41 , respectively.

Bias of uncorrected data for each treatment distance is found in Table 1. Bias for collars remaining stationary for two adjacent fixes $(0-m$ treatment $)$ was the only significant $(P<0.05)$ departure from zero among treatments. Perceived movement for the $0-m$ treatment averaged $3.9 \mathrm{~m} \pm 0.76 \mathrm{SE}$. If sign is ignored and bias is summed across all treatment distances in Table 1, total error amounted to $8.1 \mathrm{~m}$. That being so, the perceived movement of stationary collars accounted for about $48 \%$ of the total bias among treatments.

Analysis of variance of bias from differentially corrected data displayed significant time $(P=0.03)$ and treatment effects $(P=0.002)$ but no collar effects $(P=0.20)$. With differentially corrected data, mean bias across collars, times, and treatments 
Table 1. Bias of distance measures derived from uncorrected and postdifferentially corrected Lotek 2200 Global Positioning System (GPS) collars that integrated a position and were moved measured distances at hourly intervals on the Eastern Oregon Agricultural Research Center near Burns, Oregon, in December 2005.

\begin{tabular}{|c|c|c|c|c|}
\hline \multicolumn{2}{|c|}{ Uncorrected coordinates } & \multirow{2}{*}{\multicolumn{3}{|c|}{$\begin{array}{l}\text { Post differentially } \\
\text { corrected coordinates }\end{array}$}} \\
\hline \multirow{2}{*}{$\begin{array}{l}\text { Distance collar } \\
\text { was moved }(\mathrm{m})\end{array}$} & \multirow[b]{2}{*}{$\operatorname{Bias}(\mathrm{m})$} & & & \\
\hline & & $\operatorname{Bias}(\mathrm{m})$ & Time interval & $\operatorname{Bias}(\mathrm{m})$ \\
\hline 0 & $3.9 \pm 0.8^{1}$ & $1.7 \pm 0.7$ & 07-08:00 & $0.1 \pm 0.2$ \\
\hline 10 & $0.6 \pm 0.7$ & $0.5 \pm 0.2$ & 08-09:00 & $-0.1 \pm 0.2$ \\
\hline 20 & $-0.1 \pm 0.4$ & $-0.3 \pm 0.2$ & 09-10:00 & $0.3 \pm 0.1$ \\
\hline 30 & $0.5 \pm 0.6$ & $0.2 \pm 0.2$ & 10-11:00 & $0.2 \pm 0.2$ \\
\hline 40 & $0.2 \pm 0.5$ & $0.3 \pm 0.2$ & $11-12: 00$ & $0.1 \pm 0.2$ \\
\hline 50 & $-0.8 \pm 0.9$ & $-0.0 \pm 0.2$ & $12-13: 00$ & $0.4 \pm 0.2$ \\
\hline 60 & $-0.9 \pm 1.0$ & $0.4 \pm 0.3$ & $13-14: 00$ & $-0.0 \pm 0.1$ \\
\hline 70 & $-0.0 \pm 0.4$ & $-0.3 \pm 0.1$ & $14-15: 00$ & $-0.1 \pm 0.1$ \\
\hline 80 & $0.2 \pm 0.5$ & $0.7 \pm 0.5$ & $15-16: 00$ & $1.2 \pm 0.6$ \\
\hline 90 & $-0.5 \pm 0.8$ & $-0.4 \pm 0.2$ & $16-17: 00$ & $1.1 \pm 0.8$ \\
\hline Mean & $0.4 \pm 0.4$ & $0.3 \pm 0.2$ & & $0.3 \pm 0.2$ \\
\hline Sum $^{2} 450$ & 7.7 & 4.8 & & 3.6 \\
\hline
\end{tabular}

${ }^{1}$ Bold values indicate a significant departure from $0(P \leq 0.05)$.

${ }^{2}$ Sums are accumulations of absolute values.

was $0.33 \mathrm{~m} \pm 0.12$ SE. Compared with raw data $(\overline{\mathrm{X}}=0.32 \mathrm{~m} \pm 0.24 \mathrm{SE})$, the corrected mean implies differential correction offered little in the way of improved accuracy. Variability of distance measures, as indexed by the standard error, was reduced about $50 \%$ from 0.24 for raw measures to $0.12 \mathrm{~m}$ for post-differentially corrected distances.

Again, bias or the perceived movement of collars that were not moved for two adjacent fixes was the only significant departure from zero among treatments (Table 1). With differentially corrected data, error for the stationary treatment averaged $1.69 \mathrm{~m} \pm 0.70 \mathrm{SE}$. With a sum of absolute values for bias across all treatments being $5.1 \mathrm{~m}$, the stationary treatment accounted for about $33 \%$ of total error for distances measures derived from differentially corrected coordinates.

Among time intervals with differentially corrected data, significant bias occurred for the two distance measures acquired between 1500 and $1700 \mathrm{~h}$ (Table 1). These may be partially explained by the differential correction failure for the $1600 \mathrm{~h}$ records. Among treatment and control collars (total $n=14$ ), the $1600 \mathrm{~h}$ coordinates consistently suggested units were $4.7 \mathrm{~m} \pm 0.2 \mathrm{SE}$ northwest (bearing $329^{\circ} \pm 2.4^{\circ} \mathrm{SE}$ ) of their surveyed positions. Because a single coordinate in a series of records serves first as an arrival and then as a departure point when distances are derived, error for a single coordinate affects its two bounding distance measures. The distance measures on either side of the $1600 \mathrm{~h}$ coordinates accounted for about $64 \%(2.3 \mathrm{~m})$ of the total error attributed to time effects.

These issues attached to the $1600 \mathrm{~h}$ records remind us there are brief periods in which reduced satellite availability or other anomalies can affect GPS units in localized areas. In most instances differential correction can account for and rectify a large proportion of GPS error. While differential correction is not always possible, findings suggest that even a full set of uncorrected data exhibits remarkable accuracy for quantifying an animal's travels if distances between coordinates exceed normal GPS error rates.

Overall, we suggest GPS error effects on distance measures average to almost zero when collars were moved from 10 to $90 \mathrm{~m}$. With uncorrected GPS coordinates and roving collars (10 through 90-m treatments), mean error for distance measures was $0.38 \mathrm{~m} \pm 0.65 \mathrm{SE}$. After differential correction, mean error was reduced about half to $0.18 \mathrm{~m} \pm 0.24 \mathrm{SE}$ for mobile units. Instances in which GPS collars remain stationary, however, always introduce a positive bias; this suggests units have moved significantly. With uncorrected data, mean bias from the four immobile control collars was $3.93 \mathrm{~m} \pm 0.76 \mathrm{SE}$. With differentially corrected data from control collars, bias averaged $1.69 \mathrm{~m} \pm 0.70 \mathrm{SE}$.

Another explanation of error effects may be had by examining the actual travels of the 10 roving GPS collars and the four stationary controls. Each roving collar traversed $450 \mathrm{~m}$. Extrapolation of total distance traveled from corrected coordinates averaged $453.27 \mathrm{~m} \pm 1.17 \mathrm{SE}$, a fairly close approximation exhibiting about $0.73 \%$ error. The sum of perceived movements from the four immobile control collars averaged $14.70 \mathrm{~m} \pm 0.59$ SE. Again using the $450-\mathrm{m}$ travel distance of the mobile units as the denominator, stationary collars accumulated about $3.27 \%$ error.

Our discussion does not infer a stationary GPS collar is less accurate than a roving unit. Series of overestimates and underestimates of distance measures from roving units compensate for one another over time and will likely approximate zero as long as movements exceed normal position error. For stationary collars, however, the perceived distance between any two consecutive records will always be a positive value because the actual distance traversed was zero. Thus, if an animal is stationary, GPS error has no opportunity to average out. These distance accumulations are additive over time (Heezen and Tester 1967) and could become progressively more problematic when durations between position fixes are short and one acquires more records for sedentary animals.

Error associated with coordinates bracketing the $1600 \mathrm{~h}$ record is a reminder we have brief periods during which reduced satellite visibility or other anomalies may affect GPS units in localized areas. In most instances differential correction can account for and rectify large proportions of position error. We found, however, that uncorrected data exhibited remarkable accuracy for estimating distance. For animals that remain sedentary over extended periods, like ruminating herbivores, measures of accumulated travels may be positively biased if data from stationary periods are not considered.

Last, the time interval between successive GPS records should have no effect on bias for moving animals if travels exceed normal GPS error. This is supported because expanded sampling intervals do not affect error for stationary collars (Ungar et al. 2005). As this manuscript is being drafted, equipment with capacities for 1-s intervals for several weeks is being developed. Thus, the potential for examining these issues in greater detail is nearly at hand.

\section{Study 2. Filtering Fine-Scale Movement in Cattle Data}

Collar Performance. GPS collars were configured to integrate a position every $5 \mathrm{~min} 24 \mathrm{~h} \cdot$ day $^{-1}$ for a total of 4320 
Table 2. Regression models and coefficients developed by forward stepwise regressions predicting time (min) cattle rested (lying + standing) during 5-min intervals using left-right and forward-backward motion sensor counts from Lotek 2200 GPS collars worn for 15 days on the Northern Great Basin Experimental Range near Burns, Oregon, in June 2004 as independent variables. Left-right and forward-backward motion sensor counts were averages of two 2-min periods within each 5-min position integration interval and ranged from 0 to a maximum of 255 .

\begin{tabular}{|c|c|c|c|c|c|c|c|c|}
\hline \multirow[b]{2}{*}{ Collar no. } & \multicolumn{2}{|c|}{ Intercept } & \multicolumn{2}{|c|}{ L/R coefficient ${ }^{1}$} & \multirow{2}{*}{$\frac{\text { F/B coefficient }^{2}}{\text { Estimate }}$} & \multirow[b]{2}{*}{ SE } & \multirow[b]{2}{*}{ Entry order ${ }^{3}$} & \multirow[b]{2}{*}{$R^{2}$} \\
\hline & $b_{0}$ & SE & Estimate & SE & & & & \\
\hline 1 & 5.00 & 0.22 & -0.026 & 0.002 & $N A^{4}$ & NA & $\mathrm{L} / \mathrm{R}$ & 0.75 \\
\hline 2 & 4.64 & 0.18 & -0.029 & 0.002 & NA & NA & $L / R$ & 0.69 \\
\hline 100 & 4.67 & 0.19 & -0.0212 & 0.003 & -0.0234 & 0 & L/R-F/B & 0.72 \\
\hline 101 & 4.87 & 0.20 & -0.03 & 0.002 & NA & NA & $\mathrm{L} / \mathrm{R}$ & 0.72 \\
\hline 102 & 4.86 & 0.15 & -0.0259 & 0.001 & NA & NA & $\mathrm{L} / \mathrm{R}$ & 0.82 \\
\hline 156 & 5.06 & 0.24 & -0.01 & 0.003 & -0.029 & 0 & L/R-F/B & 0.72 \\
\hline 157 & 5.05 & 0.09 & -0.025 & 0.001 & NA & NA & $L / R$ & 0.94 \\
\hline 193 & 4.84 & 0.15 & -0.028 & 0.001 & NA & NA & $L / R$ & 0.85 \\
\hline 196 & 4.87 & 0.17 & -0.046 & 0.003 & NA & NA & $\mathrm{L} / \mathrm{R}$ & 0.74 \\
\hline 197 & 4.74 & 0.23 & -0.024 & 0.002 & NA & NA & $L / R$ & 0.59 \\
\hline 198 & 4.77 & 0.13 & -0.027 & 0.001 & NA & NA & $\mathrm{L} / \mathrm{R}$ & 0.87 \\
\hline
\end{tabular}

${ }^{1} \mathrm{~L} / \mathrm{R}$ indicates left-right motion sensor count.

${ }^{2} \mathrm{~F} / \mathrm{B}$ indicates forward-backward motion sensor count.

${ }^{3}$ Entry order refers to the sequence of independent variable entry into the model during forward stepwise regression.

${ }^{4} \mathrm{NA}$ indicates not applicable.

positions for each cow over 15 days. One collar malfunctioned, securing only $40.6 \%$ of its scheduled points, and those data were discarded. Including the malfunctioning unit, $94.5 \%$ of the targeted 51840 records were secured from the 12 cattleborne units. The 11 remaining collars acquired $99.94 \%$ of their scheduled records. That being so, 29 interpolated coordinates $(0.06 \%)$ were used to round out the dataset.

Cattle Observation Data. Based on visual observation of each cow's activities, we discriminated $53 \pm 1.9$ SE $(55.2 \% \pm 1.98 \%$ $\mathrm{SE})$ active and $43 \pm 1.9 \mathrm{SE}(44.8 \% \pm 1.98 \% \mathrm{SE}) 5$-min resting intervals across $8 \mathrm{~h}$. During observation sessions, GPS data suggested that cattle traveled a total of $2607 \mathrm{~m} \pm 223 \mathrm{SE}$. Perceived movement accrued by GPS records while cattle were actually resting averaged $157 \mathrm{~m} \pm 22.8 \mathrm{SE}$ translating to about a $6.0 \% \pm 1.5 \%$ SE inflation of estimated travel over the $8 \mathrm{~h}$ of observations.

Modeling Procedure. The forward, stepwise regression models predicted the number of minutes cattle were resting in each 5min interval (Table 2). With two exceptions (Table 2), the leftright motion sensor count was the first independent variable selected. Aside from the two motion sensor counts, no other independent variable entered the models, and mean $R^{2}$ across models was 0.77 (range: 0.59-0.94). Discounts of distance measures flagged by the modeling method as resting intervals during the 8-h observation periods removed $227 \mathrm{~m} \pm 58 \mathrm{SE}$ of travel.

Activity Sensor Threshold Procedure. Studies of cumulative frequency histograms over increasing values of the left-right motion sensor counts consistently implied a separation in activity levels occurred with a motion sensor count of 10 (Fig. 3). Among the 47520 records covering the 15-d grazing trial, the left-right motion sensor recorded a maximum value of 255 in 133 instances. Approximately 41\% $\pm 4.0 \%$ SE of the associated coordinates exhibited a left-right count $\leq 10$ over the $15 \mathrm{~d}$. Discounts of distance measures flagged by the activity sensor procedure as resting intervals extracted $156 \mathrm{~m} \pm 52 \mathrm{SE}$ of travel from the 8 -h observation data.

Minimum Distance Threshold Procedure. With the differentially corrected stationary collar data, mean position error was $3 \mathrm{~m}$ (range: $0.2-43.7 \mathrm{~m}$ ). Ninety percent of control collar coordinates were within $5.5 \mathrm{~m}$ of the mean (Fig. 2). Approximately $31.4 \% \pm 3.1 \%$ SE of the 47520 travel distances for collared cattle were $5.5 \mathrm{~m}$ or less over the 15 -d grazing trial. Discounts of measures flagged by the distance threshold procedure as resting intervals removed $153 \mathrm{~m} \pm 11 \mathrm{SE}$ of travel from the 8-h cattle observation data.

Combined Activity Sensor and Minimum Distance Thresholds Procedure. Combining minimum distance and activity sensor thresholds identified $26.8 \% \pm 3.0 \%$ SE of the 47520 GPS records as resting. Discounts of distance measures flagged by the combined activity/minimum distance procedure as resting intervals withdrew only $66 \mathrm{~m} \pm 6.4 \mathrm{SE}$ of travel from 8 - $\mathrm{h}$ observation data. Given that two criteria must be simultaneously satisfied to assign a resting classification with the combined procedure, one would intuitively expect fewer observations would be withdrawn.

Comparing Cattle Observations and Filtering Procedures. The regression procedure was the most accurate $(P<0.01)$ discriminator between active and resting intervals with the 8 -h cattle observation data exhibiting a 92\% success rate (Table 3 ). Ranking second, third, and fourth for classification accuracy were the activity sensor threshold, minimum distance threshold, and motion sensor/minimum distance thresholds with $84 \%, 81 \%$, and $81 \%$ success, respectively. The activity sensor technique marginally exceeded the combined distance and activity sensor method $(P<0.05)$. For three of the four filtering methods, incorrect assessments of resting cattle were responsible for the preponderance $(P<0.5)$ of error (Table 3$)$. The 
Table 3. Percentage of observations where the four filtering procedures (used to identify and remove perceived travel between successive GPS collar coordinates) correctly (C) discriminated between active and resting intervals of observed cattle in three 400-ha pastures on the Northern Great Basin Experimental Range near Burns, Oregon, in 2004. Also listed is the percentage occurrence of incorrectly classified active (A) and incorrectly classified resting $(\mathrm{R})$ intervals. Overall $\mathrm{C}$ means sharing a common uppercase letter are not significantly different $(P>0.05)$. Active $(A)$ and resting (R) means beneath a filtering procedure sharing a common letter are not significantly different $(P>0.05)$.

\begin{tabular}{|c|c|c|c|c|c|c|c|c|c|c|c|c|}
\hline \multirow[b]{2}{*}{ GPS collar } & \multicolumn{3}{|c|}{ Modeling procedure } & \multicolumn{3}{|c|}{ Minimum distance } & \multicolumn{3}{|c|}{$\mathrm{L} / \mathrm{R}$ activity sensor } & \multicolumn{3}{|c|}{$\begin{array}{l}\text { Combined distance and } \\
\text { activity sensor }\end{array}$} \\
\hline & C & A & $\mathrm{R}$ & C & A & $\mathrm{R}$ & C & A & $\mathrm{R}$ & C & $A$ & $\mathrm{R}$ \\
\hline 1 & 94.8 & 1.0 & 4.2 & 88.5 & 3.1 & 8.3 & 84.4 & 0.0 & 15.6 & 83.3 & 0.0 & 16.7 \\
\hline 2 & 86.5 & 7.3 & 6.3 & 71.9 & 5.2 & 22.9 & 81.3 & 6.3 & 12.5 & 70.8 & 3.1 & 26.0 \\
\hline 100 & 89.5 & 0.0 & 10.5 & 80.0 & 16.2 & 3.8 & 83.8 & 1.0 & 15.2 & 84.8 & 0.0 & 15.2 \\
\hline 101 & 90.6 & 1.0 & 8.3 & 77.1 & 10.4 & 12.5 & 82.3 & 1.0 & 16.7 & 77.1 & 0.0 & 22.9 \\
\hline 102 & 93.8 & 2.1 & 4.2 & 75.0 & 21.9 & 3.1 & 90.6 & 2.1 & 7.3 & 90.6 & 1.0 & 8.3 \\
\hline 156 & 86.5 & 1.0 & 12.5 & 63.5 & 11.5 & 25.0 & 59.4 & 0.0 & 40.6 & 56.3 & 0.0 & 43.8 \\
\hline 157 & 95.8 & 3.1 & 1.0 & 88.5 & 5.2 & 6.3 & 87.5 & 0.0 & 12.5 & 84.4 & 0.0 & 15.6 \\
\hline 193 & 94.8 & 1.0 & 4.2 & 84.4 & 7.3 & 8.3 & 90.6 & 0.0 & 9.4 & 85.4 & 0.0 & 14.6 \\
\hline 196 & 92.7 & 1.0 & 6.3 & 83.3 & 11.5 & 5.2 & 88.5 & 1.0 & 10.4 & 83.3 & 1.0 & 15.6 \\
\hline 197 & 88.5 & 2.1 & 9.4 & 84.4 & 3.1 & 12.5 & 79.2 & 2.1 & 18.8 & 78.1 & 0.0 & 21.9 \\
\hline 198 & 96.9 & 2.1 & 1.0 & 89.6 & 9.4 & 1.0 & 96.9 & 0.0 & 3.1 & 95.8 & 0.0 & 4.2 \\
\hline Mean & $91.9 \mathrm{~A}$ & $2.0 \mathrm{~A}$ & $6.1 \mathrm{~B}$ & $80.6 \mathrm{BC}$ & $9.5 \mathrm{~A}$ & $9.9 \mathrm{~A}$ & $84.0 \mathrm{C}$ & $1.2 \mathrm{~A}$ & 14.7B & $80.9 \mathrm{~B}$ & $0.5 \mathrm{~A}$ & $18.6 \mathrm{~B}$ \\
\hline
\end{tabular}

exception was the minimum distance procedure with a $19 \%$ error rate evenly split $(P>0.05)$ between misclassifications of active and resting cattle. Application of the modeling procedure to full 15 -day data sets suggested perceived travel accumulations, acquired while cattle were flagged as immobile, inflated measures of daily travel by $1153.6 \mathrm{~m} \pm 40.8 \mathrm{SE}$ or $15.2 \% \pm 0.7 \%$ compared to unfiltered data.

The 8-h direct observations, acquired during daylight intervals, suggested we remove $157 \mathrm{~m}$ of perceived movement from GPS estimates of an average cow's travels for the periods observed. Minimum distance and activity sensor methods closely mirrored that value with suggested discounts of 153 and $156 \mathrm{~m}$, respectively. The latter two methods, however, had error rates approaching $15 \%$ to $20 \%$ for separating resting and active intervals. While the modeling method suggested a greater deduction $(227 \mathrm{~m})$ than the direct observations, we are inclined to use the modeling procedure because of its greater likelihood $(91 \%)$ of correctly classifying resting and active intervals.

The disparity between the suggested $1153 \mathrm{~m}$ discount from daily cattle travels and the $157 \mathrm{~m}$ discount from travels accrued during the daylight observation periods deserves brief mention. We suggest the preponderance of error, or incorrectly perceived daily travel, is accrued from 1000 to $0400 \mathrm{~h}$ when cattle are sedentary and largely inactive (Ganskopp 2001). The daylight observations periods were designed to capture combinations of grazing, resting, and walking activities.

Clearly one can filter GPS collar data sets to remove positive bias associated with stationary resting periods from estimates of distance traveled using any of the four techniques. Most effective at identifying resting intervals was the procedure of observing cattle over a subset of the sampled interval, recording their activities, and developing regression models to discriminate between bouts of activity and resting for the entire data set. With this procedure, we estimated cattle travel distances were inflated by $1.15 \mathrm{~km}$ daily or about $15.2 \%$ of unfiltered estimates for the 15 days of records.

An extreme example of GPS error's potential for exaggerating travel may be had by tallying distances between successive records of the stationary collar depicted in Figure 2. Over 15 days with a 5-min sampling interval and 4320 records, perceived travel was $18.4 \mathrm{~km}$. Averaged among 15 days, this reduces to $1.2 \mathrm{~km}$ daily or about $47 \mathrm{~m}$ more than the suggested daily discount of $1153 \mathrm{~m}$. As a testament to GPS accuracy, however, all of the perceived control collar's travels occurred within a $43.6 \mathrm{~m}$ radius.

With a need to obtain direct observations of animals, the regression approach is labor intensive, and likely impractical for animals intolerant of humans. Less accurate but possibly suitable alternatives could employ motion sensor (Pépin et al. 2004) or minimum distance thresholds for discriminating active and resting intervals.

Finally, one may argue the overall value of any of these exercises. Because straight-line distance is assumed between successive GPS records, and animals seldom move in straight lines, accumulated travels are likely underestimated in all instances. The relative importance of deleting GPS error accruals from estimates of travel by an animal could be potentially quite small if they were equally or partially offset by the animal's undetected meanders. Accuracy in these cases is likely only important when hypotheses focus on travel questions or energy issues (Jeschke and Tollrian 2005; Brosh et al. 2006). When hypotheses focus on relative frequency of animals in treatments or management units, assessments of travel are of little value. Ultimately consideration of perceived travel depends on an animal's scale of movement, proportion of time the animal is inactive, the scheduled frequency of GPS records when the animal is sedentary, and one's hypothesis of interest. 


\section{IMPLICATIONS}

Given the random nature of GPS error, measures of distance between adjacent coordinates for moving GPS collars were remarkably accurate with a bias of about $0.36 \mathrm{~m}$ for distances between 10 and $90 \mathrm{~m}$. When a GPS collar was stationary, however, GPS error between a series of coordinates always generates a positive value that, in applied studies, may mistakenly be perceived as travel. The bulk of perceived movements, therefore, likely accumulate when collared animals are inactive and can inflate estimates of daily travel by cattle as much as $15 \%$. This may be important if one's focus is on energy expenditures or travel issues of animals exposed to treatments. Observing and quantifying activities of collared animals and the use of regression techniques to identify inactive periods is likely the best method for extracting perceived travels from voluminous GPS datasets. Alternative but less effective techniques include use of accompanying activity sensor data, minimum distance thresholds, or a combination of the latter two methods to identify inactive periods.

\section{LITERATURE CITED}

Agouridis, C. T., T. S. Stombaugh, S. R. Workman, B. K. Koostra, D. R. Edwards, and E. S. Vanzant. 2004. Suitability of a GPS collar for grazing studies. Transactions of the American Society of Agricultural Engineers 47:1321-1329.

Brosh, A., Z. Henkin, E. D. Ungar, A. Dolev, A. Orlov, Y. Yehuda, and Y. Aharoni. 2006. Energy cost of cows' grazing activity: use of the heart rate method and the global positioning system for direct field estimation. Journal of Animal Science 84:1951-1967.

Di Orio, A. P., R. Callas, and R. J. Schaefer. 2003. Performance of two GPS telemetry collars under different habitat conditions. Wildlife Society Bulletin 31:372-379.

GansKopp, D. C. 2001. Manipulating cattle distribution with salt and water in large arid-land pastures: a GPS/GIS assessment. Applied Animal Behaviour Science 73:251-262.
Ganskopp, D., And D. Bohnert. 2006. Do pasture scale nutritional patterns affect cattle distribution on rangelands? Rangeland Ecology and Management 59:189-196.

HeEzen, K. L., AND J. R. TeSter. 1967. Evaluation of radio-tracking by triangulation with special reference to deer movements. Journal of Wildlife Management 31:124-141.

HuRn, J. 1989. GPS: A guide to the next utility. Sunyvale, CA: Trimble Navigation Limited. $76 \mathrm{p}$.

HURN, J. 1993. Differential GPS explained. Sunyvale, CA: Trimble Navigation Limited. $55 \mathrm{p}$.

Jeschke, J. M., and R. Tollrian. Predicting herbivore feeding times. Ethology $111: 187-206$

Moen, R., J. Pastor, Y. Cohen, and C. C. Schwartz. 1996. Effects of moose movement and habitat use on GPS collar performance. Journal of Wildlife Management 60:659-668.

Mourão, G., AND I. M. MedRI. 2002. A new way of using inexpensive large-scale assembled GPS to monitor giant anteaters in short time intervals. Wildlife Society Bulletin 30:1029-1032.

Pépin, D., C. Adrodos, C. Mann, and G. Janeau. 2004. Assessing real daily distance traveled by ungulates using differential GPS locations. Journal of Mammalogy 85:774-780

Rodgers, A. R., And P. Anson. 1994. Animal-borne GPS: tracking the habitat. GPS World 5:20-32.

Rodgers, A. R., R. S. Rempel, and K. F. Aвraham. 1996. A GPS-based telemetry system. Wildlife Society Bulletin 24:559-566.

Rutter, S. M., N. A. Beresford, And G. Roberts. 1997. Use of GPS to identify grazing areas of hill sheep. Computers and Electronics in Agriculture 17:177188

Sharif, M., A. Stien, and E. M. Schetselarr. 2004. Integrated approach to predict confidence of GPS measurement. Enschede, The Netherlands: International Institute for Geo-Information Science and Earth Observation, Available at http://www.itc.nl/library/Papers_2004/peer_conf/sharif.pdf. Accessed 25 0ctober 2006

Ungar, E. D., Z. Henkin, M. Gutman, A. Dolve, A. Genizi, and D. Ganskopp. 2005. Inference of animal activity from GPS collar data on free-ranging cattle. Rangeland Ecology and Management 58:256-266.

WILcoxon, F. 1945. Individual comparisons by ranking methods. Biometrics Bulletin 1:80-83. 